\title{
Alloying and Strengthening of Gold via Rare Earth Metal Additions
}

\author{
Yuantao Ning \\ Kunming Institute of Precious Metals, Kunming 650221, Yunnan, China \\ E-mail:majun@ipm.com.cn
}

A sketch map of simplified phase diagrams for Au-RE systems has been plotted and the interactions and the alloying behaviour between gold and the rare earth (RE) metals are summarized in this paper. The solid solubilities of the rare earth metals in gold increase as their atomic number increases. The solid solubilities and alloying behaviour of yttrium and scandium are close to and similar to those of dysprosium and lutetium, respectively. The factors influencing the solid solubility are discussed. Hume-Rothery and Darken-Gurry proposed that the relationship between atomic size and electronegativity was a criterion for solid solubility. This can be revised for the alloying behaviour between gold and RE metals. The maximum solubility of RE metals in gold is greater than 1.0 at\% RE when the difference in atomic size is less than $25 \%$ and that of the electronegativity is less than 0.7 units. The relationship between the way in which the intermediate phases that exist in the various Au-RE systems are formed and their respective crystal structures are also summarized. The changes in transformation temperatures of eutectic reactions and the various intermediate phases, expressed as ratios with the melting points of gold or the $\mathrm{RE}$ metals, have been studied in relation to the atomic sizes and atomic numbers of the RE metals. These temperature ratios decrease as the atomic numbers of the RE metals increase although those for cerium and ytterbium have anomalously high values. The trends in the distribution and strengthening effect of RE metals present as trace or dilute solute in gold are discussed.

\section{GENERAL TRENDS IN THE REACTIONS BETWEEN GOLD AND OTHER ELEMENTS IN THE PERIODIC TABLE}

The reactions between gold and other elements are related to their position in the Periodic Table. As far as the features at the gold-rich end of the relevant phase diagrams of the gold alloy systems are concerned, the alloying behaviour of gold with other elements falls roughly into one of seven characteristic zones, as shown in Figure 1 (1). The elements located in Zone 1, which are near neighbours of gold in the Table, form a continuous series of solid solutions with gold, at least at elevated temperatures. Additions of the nine metals in Zone 2 lower the melting ranges of gold alloys, leading to peritectic reactions between liquid and the gold containing the solute. The transition metals in Zone 3 form 'upward peritectic reactions' with gold, namely, the melting ranges of the gold alloys rise when the transition metals are added to gold leading to peritectic reactions. The elements in Zones 4, 5 and 6, which are further from gold in the Table, form eutectic-type phase diagrams at the gold-rich end of the alloy systems. The elements in Zone 7 , which are the non-metals, form monotectic reactions with gold. Generally speaking, the division into the seven characteristic zones in Figure 1 can be accepted, except for the Au-Zn and Au-Tl systems. According to the two phase diagrams evaluated by Okamoto and Massalski, the Au-Zn system shows a eutectic reaction at $683^{\circ} \mathrm{C}$ at the gold-rich end in a complicated phase diagram, and the Au-Tl alloy is a simple eutectic system. Thus, the $\mathrm{Au}-\mathrm{Zn}$ and $\mathrm{Au}-\mathrm{Tl}$ systems really belong to Zone 6 , not to Zone 2 .

The alloying behaviour of gold with other elements is related to the electronegativity of the elements. The electronegativity is that quality of an atom which determines its relative attraction for electrons in a covalent bond. In the Periodic Table, the electronegativity of the elements increases successively from left to right within the same period and also from top to bottom within the same group. In general, the elements 


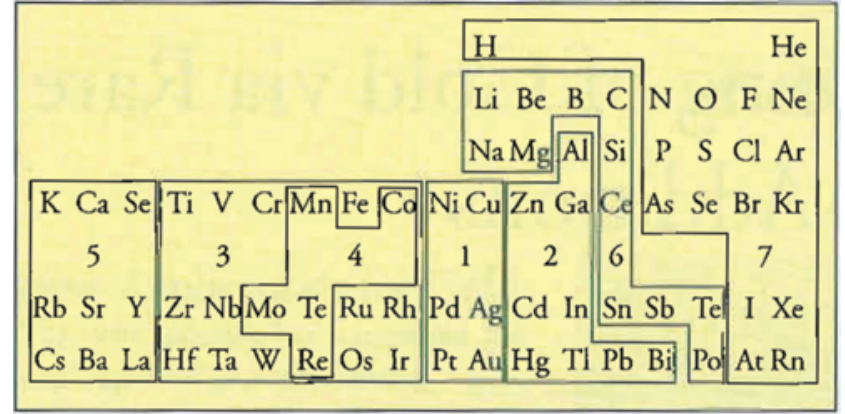

Figure 1 The distribution of the characteristic reaction zones of gold-rich alloys with other elements in the Periodic Table (after reference 1): Zone 1: Continuous series of solid solutions Zone 2: Downward peritectic reactions Zone 3: Upward peritectic reactions Zones 4, 5, 6: Eutectic reactions Zone 7: Monotectic reactions.

near to gold, which have electronegativity values close to that of gold, have a large solid solubility in or even form a continuous series of solid solutions with gold. Elements further away from gold in the Table have a greater difference in electronegativity. Consequently, the tendency to form solid solutions decreases and they are more likely to form intermediate phases and intermetallic compounds. Large differences in electronegativity and, therefore, a large mutual repellence between gold and foreign atoms even cause mutual insolubility and a tendency to form monotectic systems. Of course, the alloying behaviour of gold with other elements is dependent also on other factors such as the difference in atom size, valence, etc between gold and the solute element.

The rare earth metals discussed in this present paper are located in Zone 5 of Figure 1. They are scandium $(\mathrm{Sc})$, yttrium $(\mathrm{X})$ and the lanthanides $(\mathrm{La} \rightarrow \mathrm{Lu})$ and these all appear in Group $3 b$ in the Periodic Table. The gold-rich alloys of the Au-RE systems display eutectic reactions and have limited solid solubility.

\section{A SKETCH MAP OF SIMPLIFIED PHASE DIAGRAMS OF GOLD-RARE EARTH SYSTEMS}

Figure 2 is a sketch map of simplified phase diagrams of gold with the 17 rare earths from Sc to lutetium $(\mathrm{Lu})$. It is a concise representation of the experimental phase diagram information available from the work of Okamoto and Massalski (2). The purity of gold in all these gold-RE systems was better than $99.99 \%$ (2). The purities of RE metals in most Au-RE systems were in the range $99.5-99.9 \%$. With regard to the purity of lanthanum (La), a small number of investigators used lanthanum metal with a purity of $98-99 \% \mathrm{La}$, but most investigators used metal with a purity of $99.5-99.9 \%$ La. The investigators reported difficulty in obtaining ytterbium $(\mathrm{Yb})$ of sufficient purity, but they finally chose $\mathrm{Yb}$ having a melting point of $815^{\circ} \mathrm{C}$ and a transformation temperature of $765^{\circ} \mathrm{C}$ for the $\gamma$ to $\beta$ transformation, which were the nearest values which could be obtained to those for pure $\mathrm{Yb}\left(816\right.$ and $792^{\circ} \mathrm{C}$ respectively). Although there is only limited information on the $\mathrm{Au}-\mathrm{Sc}, \mathrm{Au}-\mathrm{Y}$ and $\mathrm{Au}-\mathrm{Eu}$ systems, the phase diagrams of other Au-RE have all been completed. The established phase diagrams are essentially similar and, as mentioned above, the gold-rich alloys have a eutectictype diagram with limited solubility of the rare earths in gold. A few alloy systems, eg Au-Sm and $\mathrm{Au}-\mathrm{Yb}$ in particular, have a greater number of intermediate phases.

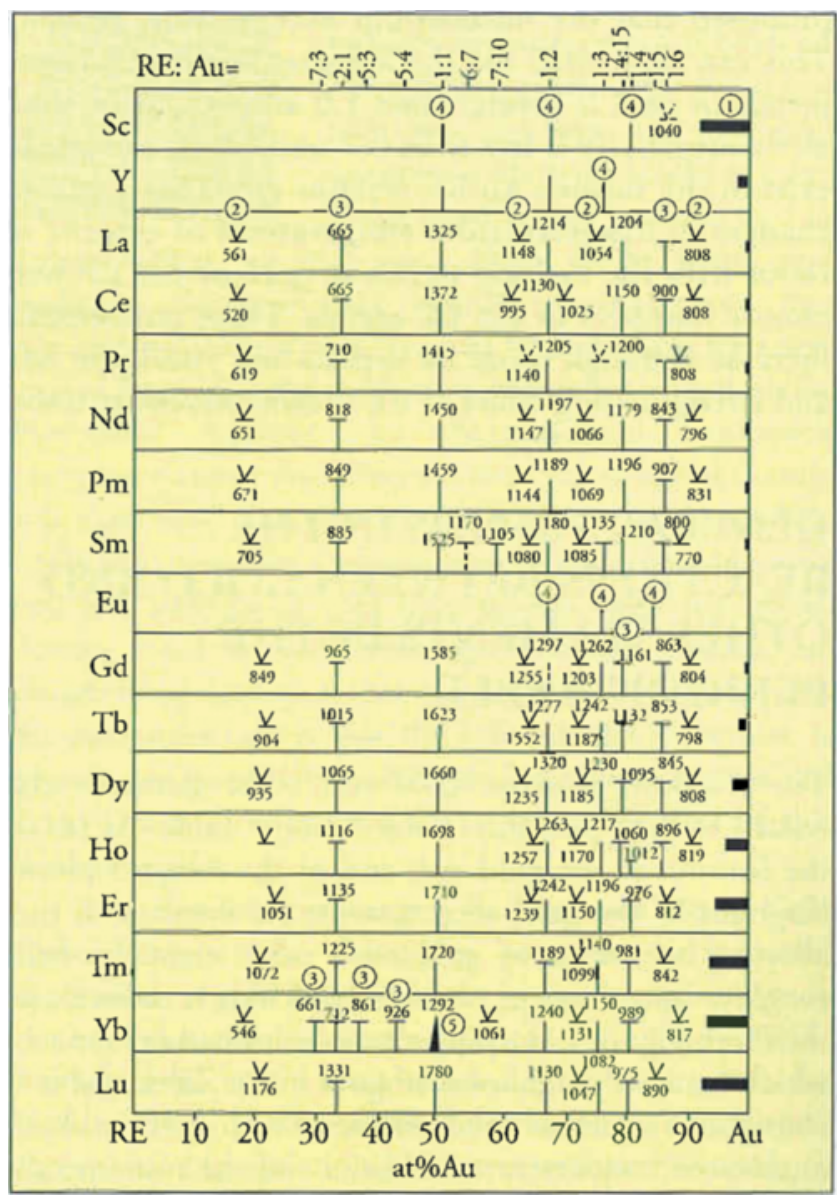

Figure 2 Sketch map of simplified phase diagrams of $A u-R E$ alloy systems (the figures on the map are temperaturcs in ${ }^{\circ} \mathrm{C}$ ): (1) limit of solid solubility; (2) eutectic reaction; (3) decomposition-type compound; (4) fusion-type compound; (5) fusion-type compound (Au-Yb) having a range of composition 


\section{THE SOLID SOLUBILITY OF THE RARE EARTH METALS IN GOLD}

The maximum solid solubilities $\left(\mathrm{C}_{\max }\right)$ of $\mathrm{RE}$ metals in gold are listed in Table 1. The dependence of $\mathrm{C}_{\max }$ on the atomic numbers $(Z)$ of RE metals is shown in Figure 3. The light RE metals (lanthanides), in terms of atomic weight, have relatively small solubilities, whereas the heavier RE metals together with Sc and Y have larger solid solubilities. The solid solubility of europium $(\mathrm{Eu})$ in gold is negligible. Although the $\mathrm{C}_{\max }$ values increase with the lanthanide contraction, the dependence of $\mathrm{C}_{\max }$ on $\mathrm{Z}$ is approximately a broken line with a lower slope for the light RE metals and a higher slope for the heavy RE metals. The point of inflexion of the broken line occurs at gadolinium (Gd). Because the alloying behaviours of scandium and yttrium with gold are similar to those of lutetium and dysprosium (Dy), respectively, their $\mathrm{C}_{\max }$ values fall just on the line of solid solubility for the heavy RE metals.

It can be seen from Table 1 that the differences in atomic size between the rare earth metals and gold are much larger than 15\% except for scandium. According to Hume-Rothery's criterion, which states that the range of solid solubility is limited if the atomic size difference is greater than $15 \%$, the atomic size differences seen here should be unfavourable for a large solid solubility of RE in Au. In fact, however, the solid solubilities of the heavy RE metals in gold are close to or above $1.0 \mathrm{at} \%$. Similarly, the differences in electronegativity between the RE metals and gold are greater than the value given by the criterion of Darken-Gurry, which states that the difference should be less than 0.4 units for extensive solid solubility. In Table 1 , the electronegativity of gold is 1.9 , the value given by Waber (9) instead of 2.3 given by Gordy (6), because Waber et al considered that the value of 2.3 is too high to explain the metallurgical features relating to the formation of solid solutions. Even so, the

Table 1 The Maximum Solid Solubility $\left(C_{\max }\right)^{*}$ of Rare Earths in Gold and Other Relevant Parameters**

\begin{tabular}{|c|c|c|c|c|c|c|}
\hline RE & $\mathrm{C}_{\max }, \mathrm{at} \%$ & r,nm & $\mathbf{x}$ & $\mathbf{v}$ & $\Delta \mathbf{r} / \mathbf{r}_{\mathrm{Au}}, \%$ & $\Delta \mathbf{X}$ \\
\hline Sc & 8.8 & 0.1641 & 1.27 & 3 & 13.9 & 0.63 \\
\hline$Y$ & 2.0 & 0.1801 & 1.20 & 3 & 25.0 & 0.70 \\
\hline $\mathrm{La}$ & 0.1 & 0.1879 & 1.17 & 3 & 30.5 & 0.73 \\
\hline $\mathrm{Ce}$ & 0.1 & 0.1825 & 1.21 & 3 & 26.7 & 0.69 \\
\hline $\operatorname{Pr}$ & 0.1 & 0.1828 & 1.20 & 3 & 26.6 & 0.70 \\
\hline $\mathrm{Nd}$ & 0.2 & 0.1821 & 1.19 & 3 & 26.5 & 0.71 \\
\hline $\mathrm{Pm}$ & - & 0.1811 & - & 3 & 25.7 & - \\
\hline Sm & 0.3 & 0.1804 & 1.18 & 3 & 25.3 & 0.72 \\
\hline $\mathrm{Eu}$ & 0 & 0.2042 & 1.20 & 2 & 41.8 & 0.70 \\
\hline Gd & 0.7 & 0.1801 & 1.20 & 3 & 25.1 & 0.7 \\
\hline $\mathrm{Tb}$ & 1.5 & 0.1783 & 1.21 & 3 & 23.8 & 0.69 \\
\hline Dy & 2.3 & 0.1774 & 1.21 & 3 & 23.2 & 0.69 \\
\hline Ho & 3.92 & 0.1766 & 1.21 & 3 & 22.7 & 0.69 \\
\hline $\mathrm{Er}$ & 5.7 & 0.1757 & 1.22 & 3 & 22.0 & 0.68 \\
\hline $\mathrm{Tm}$ & 6.5 & 0.1746 & 1.22 & 3 & 21.3 & 0.68 \\
\hline $\mathrm{Yb}$ & 6.9 & 0.1740 & 1.21 & 3 & 20.8 & 0.69 \\
\hline Lu & 7.7 & 0.1735 & 1.22 & 3 & 20.5 & 0.68 \\
\hline $\mathrm{Au}$ & - & 0.1440 & 1.9 & 1 & - & \\
\hline
\end{tabular}

* The data for the solid solubility of $\mathrm{La}$ and $\mathrm{Ce}$ in Au are taken from reference(4) and other solid solubility data are taken from reference(2). $* * r=$ atomic radius; $X=$ electronegativity; $V=$ valence; $\Delta r / r_{A u}=$ the relative atomic size difference between $R E$ and $A u ; \Delta X=$ the difference in electronegativity between RE and $\mathrm{Au}$. 


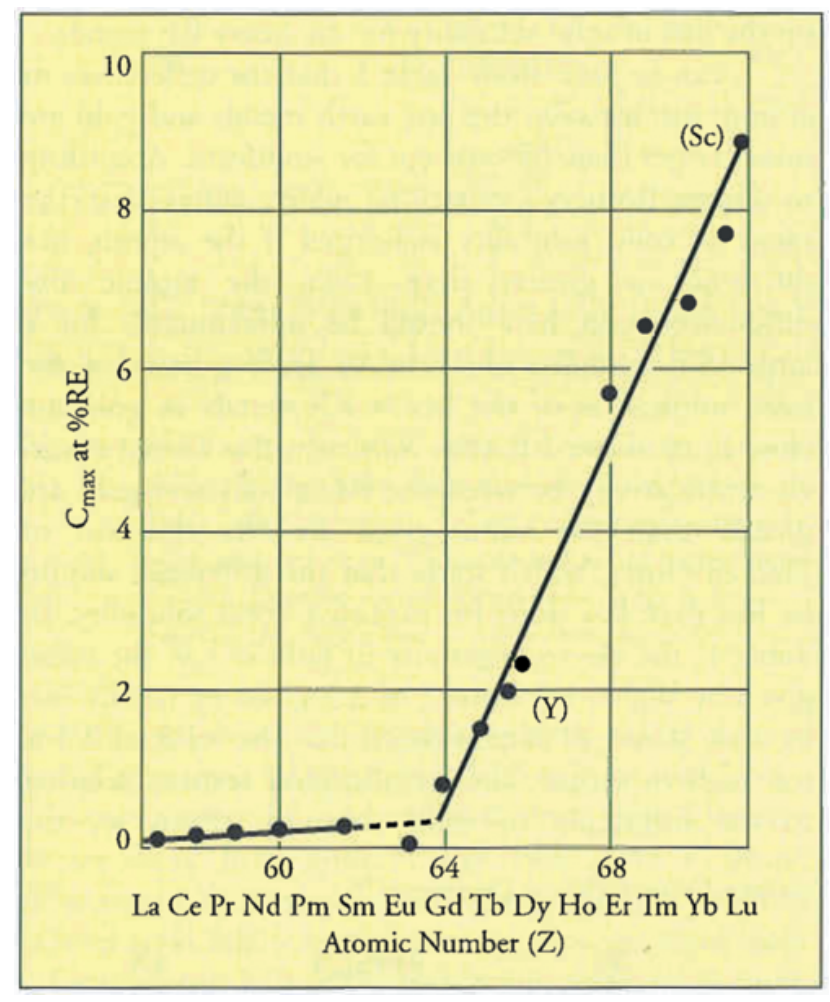

Figure 3 Dependence of the maximum solid solubility $C_{\text {max }}$ of $R E$ in gold on the atomic numbers $Z$ of the RE metals

differences in electronegativity between the RE metals and gold (with the exception of Sc) are still greater than 0.7 units. This indicates that the criteria of Hume-Rothery and Darken-Gurry are not relevant to the solid solubility of RE metals in gold.

A large electronegativity difference can cause electron migration between solvent and solute atoms during alloying. The electron migration $(\Delta \mathrm{z})$ in a solid solution is proportional to the difference in electronegativity (7) as shown by Equation (1):

$$
\Delta \mathrm{z}=1.2(1-\mathrm{C}) \Delta \Phi
$$

where $\mathrm{C}$ is the solute concentration and $\Delta \Phi$ is Miedema's electronegativity difference (7), which should be proportional to Pauling's electronegativity difference $\Delta X$. So, when gold is alloyed with RE metals, the electron migration from the RE metal to gold means that the electronegativity of the RE metal increases and that of gold decreases. At the same time, the atomic radii of the RE metals decrease and that of gold increases. Therefore, the differences in both electronegativity and atomic size between RE and gold will decrease. This is conducive to having a greater solid solubility.
The apparent atomic radii $\left(\Delta_{\mathrm{r}}\right)$ of RE metals in gold alloys have been obtained from reference 3 , and these are given in Table 2 . The relative differences $\left(\Delta_{\mathrm{r}} / \mathrm{r}_{\mathrm{Au}}\right)$ between the apparent atomic radii of RE and the atomic radius of gold are listed also in Table 2 . It can be seen that the solid solubilities of RE metals increase when the $\Delta_{\mathrm{r}} / \mathrm{r}_{\mathrm{Au}}$ values are less than $15 \%$ and they decrease rapidly when the values are greater than $15 \%$. In this sense, the solid solubility of RE in gold obeys the Hume-Rothery criterion on the effect of atomic size.

If the parameters $\Delta r / r_{A u}$ from Table 1 and $\Delta r / r_{A u}$ from Table 2 are compared, it can be seen that some regulation of atomic size and electronegativity during alloying exists when $\Delta r / r_{A u}<25 \%$ but it will be small when $\Delta \mathrm{r} / r_{\mathrm{Au}}>25 \%$ (3). Hence, Hume-Rothery's criterion can be revised for the solid solubility of RE metals in gold such that the solid solubility will be greater than $1.0 \mathrm{at} \% \mathrm{RE}$ when the atomic size difference $\left(\Delta \mathrm{r} / \mathrm{r}_{\mathrm{Au}}\right)$ is less than $25 \%$ and the difference in electronegativity is less than 0.7 units between the RE metal and gold. The critical changeover occurs at gadolinium $(\mathrm{Gd})$ and it is the reason why the heavier RE metals (in terms of atomic weight) have a greater solid solubility in gold.

\section{THE SOLID SOLUBILITY OF GOLD IN THE RARE EARTH METALS}

The majority of the RE metals undergo allotropic changes below their melting points and the solid solubility of gold in the high temperature allotropes of $\mathrm{RE}$ metals is higher than in their low temperature modifications. For example, the solid solubility of gold

Table 2 The Relationship between Apparent Atomic Radii, Apparent Size Difference and Solubility of RE Metals in Gold, after Reference (3)

$\begin{array}{cccc}\text { RE } & \mathbf{r}^{\prime}, \mathbf{n m} & \Delta \mathbf{r}^{\prime} / \mathbf{r}_{\text {Au, }} \% & \mathbf{C}_{\max }(\mathbf{R E} \text { in Au), at\%RE } \\ \text { Sc } & 0.1507 & 4.5 & 8.8 \\ \text { Lu } & 0.1629 & 13.0 & 7.7 \\ \text { Yb } & 0.1619 & 12.3 & 6.9 \\ \text { Tm } & 0.1644 & 14.0 & 6.5 \\ \text { Er } & 0.1656 & 14.8 & 5.7 \\ \text { Dy } & 0.1689 & 17.1 & 2.3 \\ \text { Tb } & 0.1712 & 18.7 & 1.5 \\ \text { Gd } & 0.1772 & 22.8 & 0.7\end{array}$


in $\alpha-\operatorname{Pr}$ and $\beta-\operatorname{Pr}$ is about 0.12 and $1.56 \mathrm{ar} \% \operatorname{Pr}$, and in $\alpha-S_{m}$ and $\beta-S m$ is about 0.2 and 0.3 at $\% \mathrm{Sm}$, respectively (8). However, according to the phase diagrams of Au-RE systems evaluated by Okamoto and Massalski (2), the solid solubilities of gold in the great majority of RE metals are negligible. This is not in agreement with the relationship between valence and the extent of solid solubility when the valences of the $\mathrm{RE}$ metals are compared with that of gold.

\section{INTERMEDIATE PHASES IN GOLD- RARE EARTH ALLOY SYSTEMS}

Thirteen types of stoichiometric compounds are known to exist in Au-RE alloy systems. The RE:Au atomic ratios of these thirteen types are 1:6, 1:5, 1:4, 14:51, 1:3, 1:2, $7: 10,6: 7,1: 1,5: 4,5: 3,2: 1$ and $7: 3$ ranged in order of increasing $\mathrm{RE}$ content. The gold-rich compounds $\mathrm{Au}_{6} \mathrm{RE}$, $\mathrm{Au}_{5} \mathrm{RE}$ and $\mathrm{Au}_{4} \mathrm{RE}$ are all decomposition-type compounds, otherwise known as incongruent melting compounds, which are formed by peritectic reactions. The compounds $A_{51} R_{14}$ which consist of gold and the light $\mathrm{RE}$ metals are congruent melting compounds, referred to here as fusion-type compounds, that form directly from the melt, whereas those consisting of gold and the heavy RE metals are decomposition-type compounds. In contrast, the compounds $\mathrm{Au}_{3} \mathrm{RE}$ consisting of gold and the heavy RE metals are fusiontype compounds. The $\mathrm{Au}_{2} \mathrm{RE}$ compounds are fusion-type except for $\mathrm{Au}_{2} \mathrm{Tm}$ and $\mathrm{Au}_{2} \mathrm{Lu}$ which are decompositiontype. All AuRE compounds are the fusion-type.

The RE-rich compounds are all of the decomposition-type, where they are known to exist. These are $A u_{4} Y_{5}, A u_{3} Y_{5}, A u_{3} Y_{7}$ and $A u R E_{2}$. $A_{u R E}$ compounds exist for the other RE metals with the exceptions of the Au-Sc, Au-Y and Au-Eu systems where the $A_{u R E}$ phase has not been found.

The distribution of the compounds in Au-RE alloy systems is summarized in Figure 4 together with their mechanism of formation (9).

The crystal structures of the thirteen types of intermediate compounds are listed in Table 3. Some compounds, which exhibit the same stoichiometry, such as ${A u_{6}}_{6} \mathrm{RE}, \mathrm{Au}_{3} \mathrm{RE}, \mathrm{Au}_{2} \mathrm{RE}$ and $\mathrm{AuRE}$, have a different crystal structure type depending on whether the RE metal is a light or heavy RE metal. Other compounds undergo a polymorphic transformation. For example, $\mathrm{PrAu}_{2}$ has an orthorhombic $\mathrm{CeCu}_{2}$-type of structure at low temperatures $\left(\alpha-\mathrm{PrAu}_{2}\right)$ and a tetragonal $\mathrm{NdAu}_{2}$-type structure at high temperatures $\left(\beta-\mathrm{PrAu}_{2}\right)$. The orthorhombic $\mathrm{CeCu}_{2}$-type structure has been observed in $\mathrm{NdAu}_{2}$ samples but it is thought to be a metastable form (10). The AuRE compounds also display polymorphic transformations. The structure type transforms from $\mathrm{CsCl}-\mathrm{CrB}-\mathrm{FeB}$-type as the temperature decreases from high to low temperature. The structures of compounds in $\mathrm{Au}-\mathrm{Pm}$ systems have not yet been determined, but it has been assumed that the Au-Pm system has the same set of intermediate phases with the same structures as in the Au-Nd system (2).

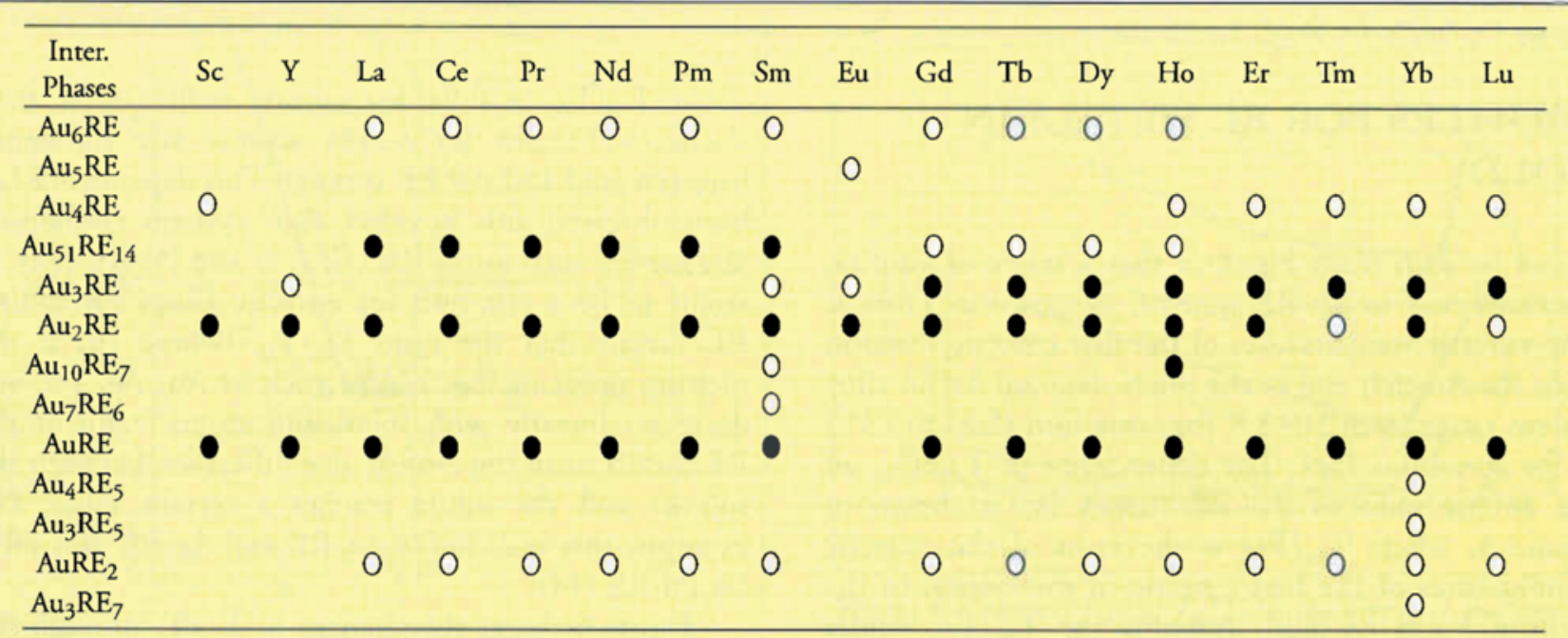

O Decomposition-type compands formed from peritectic reation;

- Fusion-type compounds formed from melting

Figure 4 Intermediate phases in Au-RE alloy systems and their mechanism of formation 
Table 3 The Distribution of Intermediate Phases in Au-RE Systems with their Crystal Structure Types

\begin{tabular}{|c|c|c|c|c|c|}
\hline \multirow[t]{2}{*}{ Compounds } & \multirow[t]{2}{*}{ Prototype } & \multicolumn{3}{|c|}{ Lattice Parameters, nm } & \multirow{2}{*}{$\begin{array}{c}\text { Alloy Systems Au-RE } \\
\text { RE }=\end{array}$} \\
\hline & & $\mathbf{a}$ & $\mathbf{b}$ & c & \\
\hline \multirow[t]{2}{*}{$\mathrm{Au}_{6} \mathrm{RE}$} & $\mathrm{Au}_{6} \mathrm{Pr}$ & $0.774-0.780$ & $0.772-0.778$ & $0.907-0.908$ & $\mathrm{La}, \mathrm{Ce}, \mathrm{Pr}, \mathrm{Nd}$ \\
\hline & $\mathrm{Au}_{6} \mathrm{Ho}$ & $1.029-1.039$ & & $0.960-0.976$ & Sm, Gd,Tb, Dy, Ho \\
\hline $\mathrm{Au}_{5} \mathrm{RE}$ & $\mathrm{CaCu}_{5}$ & 0.5560 & & 0.4584 & Eu \\
\hline $\mathrm{Au}_{4} \mathrm{RE}$ & $\mathrm{MoNi}_{4}$ & $0.6549-0.6653$ & & $0.4039-0.4174$ & Ho,Er,Tm,Yb,Lu,Sc \\
\hline $\mathrm{Au}_{51} \mathrm{RE}_{14}$ & $\mathrm{Ag}_{51} \mathrm{RE}_{14}$ & I.255-1.287 & & $0.9135-0.9388$ & $\mathrm{La}, \mathrm{CePr}, \mathrm{Nd}, \mathrm{Sm}, \mathrm{Gb}, \mathrm{Tb}, \mathrm{Dy}, \mathrm{Ho}$ \\
\hline \multirow[t]{3}{*}{$\mathrm{Au}_{3} \mathrm{RE}$} & $\mathrm{Cu}_{3} \mathrm{Ti}$ & $0.5962-0.6377$ & $0.4921-0.5004$ & $0.5072-0.5099$ & Sm,Gd,Tb,Dy,Ho,Er,Tm,Yb,Lu,Y \\
\hline & Tetragonal & 1.1519 & & 0.8445 & Eu \\
\hline & $\mathrm{CeCu}_{2}$ & $0.4528-0.4672$ & $0.7040-0.7330$ & $0.8068-0.8178$ & $\mathrm{La}, \mathrm{Ce}, \mathrm{Pr}, \mathrm{Nd}, \mathrm{Eu}$ \\
\hline \multirow[t]{2}{*}{$\mathrm{Au}_{2} \mathrm{RE}$} & $\mathrm{NbAu}_{2}$ & $1.569-1.600$ & & $0.9243-0.9360$ & $\mathrm{Pr}, \mathrm{Nb}, \mathrm{Sm}$ \\
\hline & $\mathrm{MoSi}_{2}$ & $0.351-0.373$ & & $0.873-1.090$ & Sc, Y, heavy RE from Gd to Lu \\
\hline $\mathrm{Au}_{10} \mathrm{RE}_{7}$ & $\mathrm{Au}_{10} \mathrm{Sm}_{7}$ & 1.040 & & 2.8254 & Sm \\
\hline \multirow[t]{2}{*}{$\mathrm{Au}_{7} \mathrm{RE}_{6}$} & $\mathrm{Au}_{7} \mathrm{Sm}_{6}$ & 0.8110 & $\alpha=\mid 14.04^{\circ}$ & & $\mathrm{Sm}$ \\
\hline & $\mathrm{FeB}$ & $0.732-0.752$ & $0.446-0.469$ & $0.587-0.596$ & $\mathrm{La}, \mathrm{Ce}, \mathrm{Pr}, \mathrm{Nd}, \mathrm{Yb}$ \\
\hline \multirow[t]{2}{*}{ AuRE } & $\mathrm{CrB}$ & $0.365-0.390$ & $1.081-1.114$ & $0.464-0.475$ & $\mathrm{La}, \mathrm{Ce}, \mathrm{Pr}, \mathrm{Nd}, \mathrm{Sm}, \mathrm{Gd}, \mathrm{Tb}, \mathrm{Dy}, \mathrm{Ho}, \mathrm{Er}, \mathrm{Tm}$ \\
\hline & $\mathrm{CsCl}$ & $0.337-0.386$ & & & $\begin{array}{l}\mathrm{Pr}, \mathrm{Nd}, \mathrm{Sm}, \mathrm{Sc}, \mathrm{Y} \text { heavy RE from } \\
\text { Gd to Lu }\end{array}$ \\
\hline $\mathrm{Au}_{4} \mathrm{RE}_{5}$ & $\mathrm{Sm}_{5} \mathrm{Ge}_{4}$ & 0.7752 & 1.502 & 0.788 & $\mathrm{Yb}$ \\
\hline $\mathrm{Au}_{3} \mathrm{RE}_{5}$ & $\mathrm{Cr}_{5} \mathrm{~B}_{3}$ & 0.7793 & & 1.426 & $\mathrm{Yb}$ \\
\hline $\mathrm{AuRE}_{2}$ & $\mathrm{Co}_{2} \mathrm{Si}$ & $0.738-0.691$ & $0.51 \mid-0.482$ & $0.941-0.870$ & all RE except Sc,Y and Eu \\
\hline $\mathrm{Au}_{3} \mathrm{RE}_{7}$ & $\mathrm{Th}_{7} \mathrm{Fe}_{3}$ & 1.0372 & & 0.6514 & $\mathrm{Yb}$ \\
\hline
\end{tabular}

*Heavy RE, Gd, Tb, Dy, Ho, Er,Tm, Yb, Lu.

\section{PROFILES FOR RE METALS IN GOLD}

It can be seen from Figure 2 that a series of eutectic reactions exist in Au-RE systems, as shown in Table 4. The eutectic temperatures of the first eutectic reaction from the Au-rich end of the phase diagram for an alloy system range from $1043 \mathrm{~K}$ for samarium $(\mathrm{Sm})$ to 1313 $\mathrm{K}$ for scandium $(\mathrm{Sc})$. The dependence of $\mathrm{T}_{\text {eu }} / \mathrm{T}_{\mathrm{Au}}$ on the atomic radii of the RE metals (4) is shown in Figure 5, where $T_{e u} / T_{A u}$ is the ratio of the eutectic temperatures of the first eutectic in the system to the melting point of gold. Initially, the $\mathrm{T}_{\mathrm{eu}} / \mathrm{T}_{\mathrm{Au}}$ values decrease linearly from that for $S c$ as the atomic radii of the RE metals increase. This is in accord with the observation of Hume-Rothery (11) for simple eutectic systems. The decrease ceases and remains constant at about $\mathrm{T}_{\text {eu }} / \mathrm{T}_{\mathrm{Aul}}=0.81$ for atomic radii greater than about $0.175 \mathrm{~nm}$ (or $>21 \%$ atomic size difference between gold and the RE metals). This dependence has been observed also in other alloy systems containing rare earths, such as $\mathrm{Ag}-\mathrm{RE}(12,13)$ and Pd-RE (14). It seems to be a criterion for eutectic alloys containing RE metals that the ratio $T_{e u} / T_{m}$ (where $T m$ is the melting point of the solvent such as $\mathrm{Au}, \mathrm{Ag}, \mathrm{Pd}$, etc) decreases linearly with increasing atomic radii of the $\mathrm{RE}$ metals until the atomic size difference between the solvent and the solute reaches a certain value. For example, this is $21 \%$ for Au-RE and Ag-RE and 28\% for Pd-RE (14).

Figure 6 shows the changes in $T_{\mathrm{eu}} / T_{\mathrm{r}}$ through the series of RE metals from lanthanum ( $\mathrm{La}$ ) to lutetium $(\mathrm{Lu})$, where $\mathrm{T}_{\mathrm{eu}}$ are the temperatures of the first $\left(\mathrm{E}_{1}\right)$ and third $\left(\mathrm{E}_{3}\right)$ eutectic reactions from the Au-rich end of the phase diagrams and $T_{r}$ is the melting point of 
Table 4 The Eutectic Reactions in Au-RE Alloy Systems

\begin{tabular}{|c|c|}
\hline Eutectic Systems & Eutectic reaction \\
\hline \multirow{3}{*}{$\begin{array}{c}\text { First } \\
\text { (gold-rich end) }\end{array}$} & $L=(A u)+A u_{6} R E$ \\
\hline & $L=(A u)+A u_{5} R E$ \\
\hline & $L=(A u)+A u_{4} R E$ \\
\hline \multirow{2}{*}{ Second } & $\mathrm{L}=\mathrm{Au}_{51} \mathrm{RE}_{14}+\mathrm{Au}_{2} \mathrm{RE}$ \\
\hline & $\mathrm{L}=\mathrm{Au}_{3} \mathrm{RE}+\mathrm{Au}_{2} \mathrm{RE}$ \\
\hline \multirow{2}{*}{ Third } & $\mathrm{L}=\mathrm{Au}_{2} \mathrm{RE}+\mathrm{AuRE}$ \\
\hline & $\mathrm{L}=\mathrm{Au}_{2} \mathrm{RE}+\mathrm{Au} \mathrm{u}_{7} \mathrm{RE}_{10}$ \\
\hline \multirow[t]{2}{*}{$\begin{array}{c}\text { Fourth } \\
\text { (RE-rich end) }\end{array}$} & $L=A u R E_{2}+(R E)$ \\
\hline & $\mathrm{L}=\mathrm{Au}_{3} \mathrm{RE}_{7}+(\mathrm{RE})$ \\
\hline
\end{tabular}

the $\mathrm{RE}$ metal. The ratios $\mathrm{T}_{\mathrm{eu}} / \mathrm{T}_{\mathrm{r}}$ decrease gradually through the series $\mathrm{La}$ to $\mathrm{Lu}$, but there are anomalously high values at cerium $(\mathrm{Ce})$ and ytterbium $(\mathrm{Yb})$. In addition, the ratio $\mathrm{T}_{\mathrm{eu}} / \mathrm{T}_{\mathrm{r}}$ for the second eutectic reaction from the gold-rich end obeys similar rules to the first $\left(E_{1}\right)$ and third $\left(E_{3}\right)$ eutectic systems.

Changes of the ratios $T_{m} / T_{r}$ and $T_{p} / T_{r}$ through the series of RE metals from $\mathrm{La}$ to $\mathrm{Lu}$ are shown in Figure 7 , where $T_{m}$ are the melting points of the fusion-type

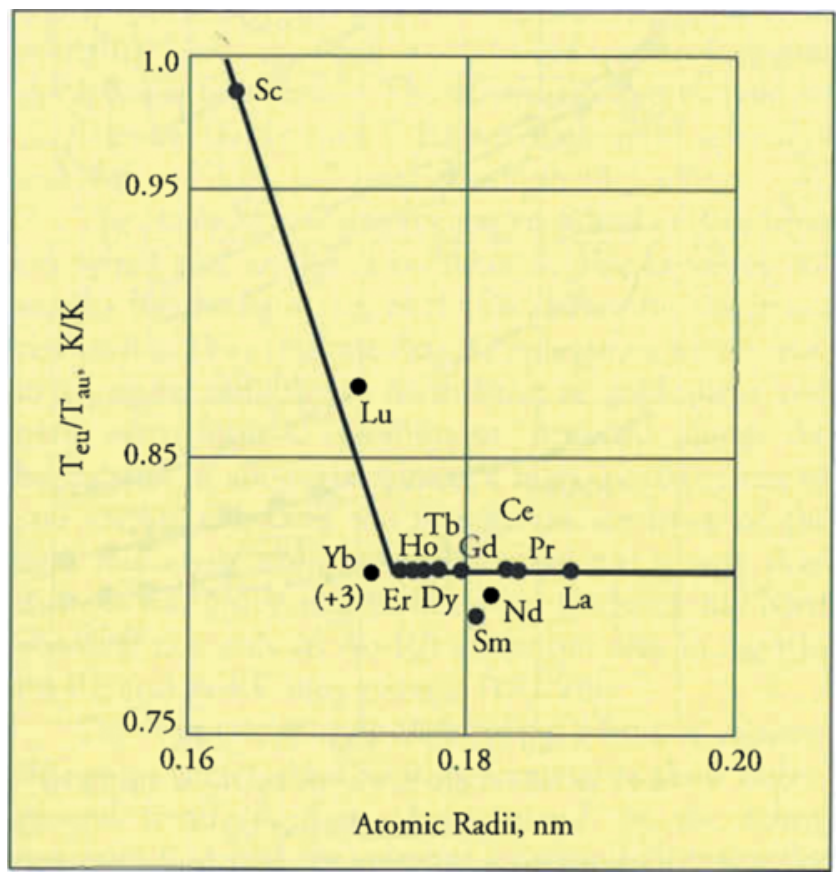

Figure $5 T_{e u} / T_{a u}$ versus atomic radii of Rare Earth (RE) metals in the first eutectic system of $A u-R E$ alloy systems

\author{
Alloy system, RE= \\ La, Ce, Pr, Nd,Pm, Sm, Gd, Tb, Dy, Ho \\ Eu \\ $\mathrm{Sc}, \mathrm{Er}, \mathrm{Tm}, \mathrm{Yb}, \mathrm{Lu}$ \\ $\mathrm{La}, \mathrm{Ce}, \mathrm{Pr}, \mathrm{Nd}, \mathrm{Pm}$ \\ $\mathrm{Sm}, \mathrm{Gd}, \mathrm{Tb}, \mathrm{Dy}, \mathrm{Ho}, \mathrm{Er}, \mathrm{Tm}, \mathrm{Yb}, \mathrm{Lu}$ \\ $\mathrm{La}, \mathrm{Ce}, \mathrm{Pr}, \mathrm{Nd}, \mathrm{Pm}, \mathrm{Gd}, \mathrm{Tb}, \mathrm{Dy}, \mathrm{Ho}, \mathrm{Er}, \mathrm{Yb}$ \\ Sm \\ La, Ce, Pr, Nd, Pm, Sm, Gd, Tb, Dy, H0, Er, \\ Tm, Lu \\ $\mathrm{Yb}$
}

compounds and $T_{p}$ are the decomposition (peritectic) temperatures of the decomposition-type compounds. It can be seen that these show the same trend as that seen with $\mathrm{T}_{\mathrm{eu}} / \mathrm{T}_{\mathrm{r}}$ (Figure 6). The alloying behaviour of cerium (Ce), europium (Eu), and ytterbium (Yb) with gold, silver, and palladium can be anomalous, and this is related to their valence and the stability of their $4 f$ electron configuration. Cerium can have 3, 4 and variable valence depending on the element with which it is alloying. In the $\mathrm{Au}-\mathrm{Ce}$ and $\mathrm{Ag}-\mathrm{Ce}$ systems, cerium is trivalent (32) : and the reason for the unusually high reduced temperatures in these systems (13) is not yet clear. Ytterbium takes a variable valence in its gold alloys: for example, it is trivalent in solid solution (see

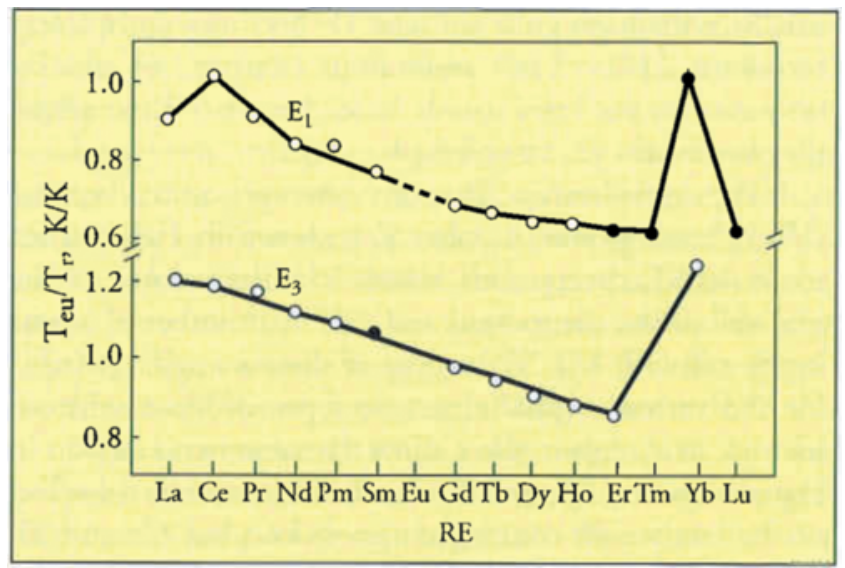

Figure 6 Changes of ratios $T_{e u} / T_{r}$ for the first $\left(E_{1}\right)$ and third $\left(E_{3}\right)$ eutectic reactions through the series of $R E$ metals from $L a$ to $L u . E_{1}$ (blank circle, reaction between $A u$ $A u_{6} R E$; solid circle, between $A u-A u_{4} R E$ ); $E_{3}$ (blank circle, reaction between $A u_{2} R E-A u R E$; solid circle between $\left.A u_{2} R E-A u_{10} S m_{7}\right)$ 


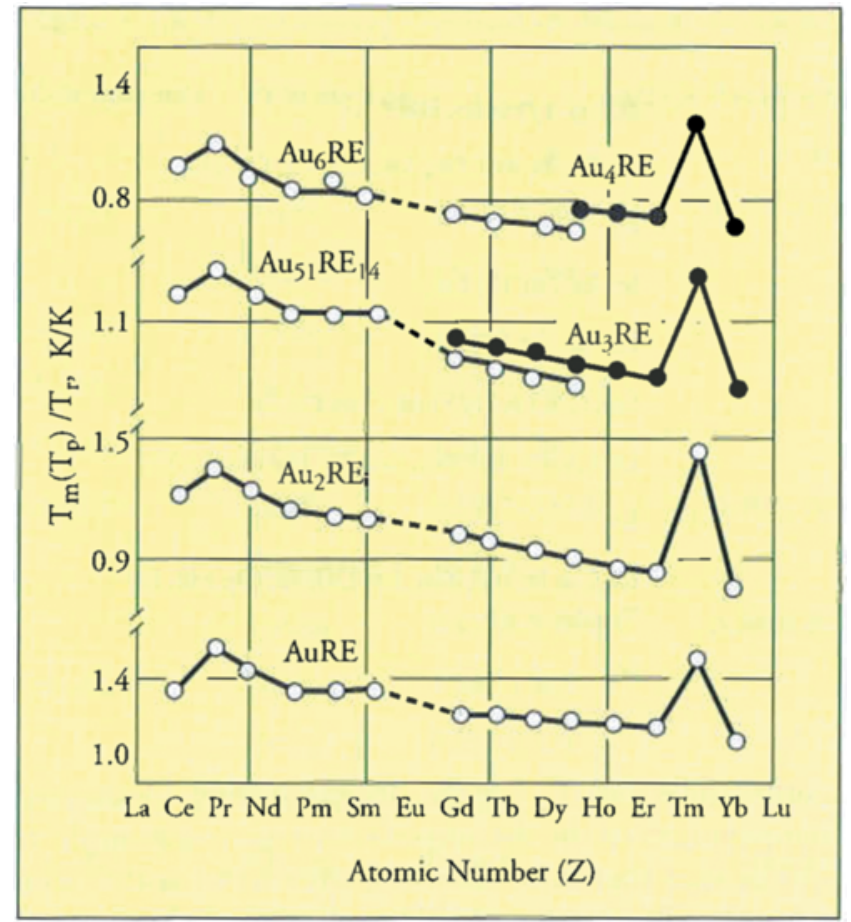

Figure 7 Changes of the ratios $T_{m} / T_{r}$ and $T_{p} / T_{r}$ for the intermediate phases $A u_{x} R E$ through the series of $R E$ metals from La to $L u . T_{m}$ is the melting point of fusion-type compounds, $T_{p}$ is the decomposition temperature of decomposition-type compounds and $T$, is the melting point of RE metals

Table 1) and is di- or trivalent in its compounds, depending on the concentration of gold present. $\mathrm{Yb}(\mathrm{II})$ compounds first appear, then with increasing gold content, compounds with intermediate valence, and finally, with high gold content $\mathrm{Yb}$ becomes completely tervalent (32). The anomalous nature of Au-Eu systems is not discussed here because this phase diagram is not yet established

The relationship between average atom volume $(\mathrm{V} / \mathrm{n})^{1 / 3}$ and atomic number $\mathrm{Z}$ is shown in Figure 8 for some $\mathrm{Au}_{\mathrm{x}} \mathrm{RE}$ compounds, where $\mathrm{V}$ is the volume of the unit cell of the compound and $n$ is the number of atoms in the cell $(10,15)$. The values of the parameter $(\mathrm{V} / \mathrm{n})^{1 / 3}$ for the various crystal structure types decrease with an increase in Z. Again, these show the same trend as seen in Figure 7 for $T_{m} / T_{r}$ and $T_{p} / T_{r}$. In all situations, the effect of the lanthanide contraction is obvious but $\mathrm{Ce}$ and $\mathrm{Yb}$ often show unusual effects. For compounds having the same stoichiometry and polymorphic transformation, such as AuRE, the crystal structure with the lowest $(\mathrm{V} / \mathrm{n})^{1 / 3}$ value is the most stable. Generally, the larger the volume contraction of the compound formed, the larger is its negative free energy of formation (15). From Figure
8 , it follows that $\Delta \mathrm{G}_{\mathrm{f}}(\mathrm{CsCl})<\Delta \mathrm{G}_{\mathrm{f}}(\mathrm{FeB})<\Delta \mathrm{G}_{\mathrm{f}}(\mathrm{CrB})$ Therefore, of the three crystal structures of AuRE compounds, the CsCi-type structure is the most stable. In general, compounds with congruent melting points such as AuRE have negative energies of formation, eg -111, -109 and $-92 \mathrm{KJ} / \mathrm{mol}$ are obtained for AuSc, AuY, and AuLa respectively using Miedema's model for the heat of formation of alloys (33). It is a general rule that the larger the volume contraction of the compound formed, the more negative is its free energy of formation (15).

\section{THE DISTRIBUTION AND STRENGTHENING EFFECT OF RARE EARTH METALS IN GOLD}

Golyev (16) proposed a set of parameters to describe the distribution of a solute in an alloy. Taking $\alpha$ as the maximum solid solubility and $\beta$ as the solute concentration in the liquid alloy at the same temperature, the parameter $\omega=\alpha / \beta$ can express the way in which the solute is distributed in the alloy.

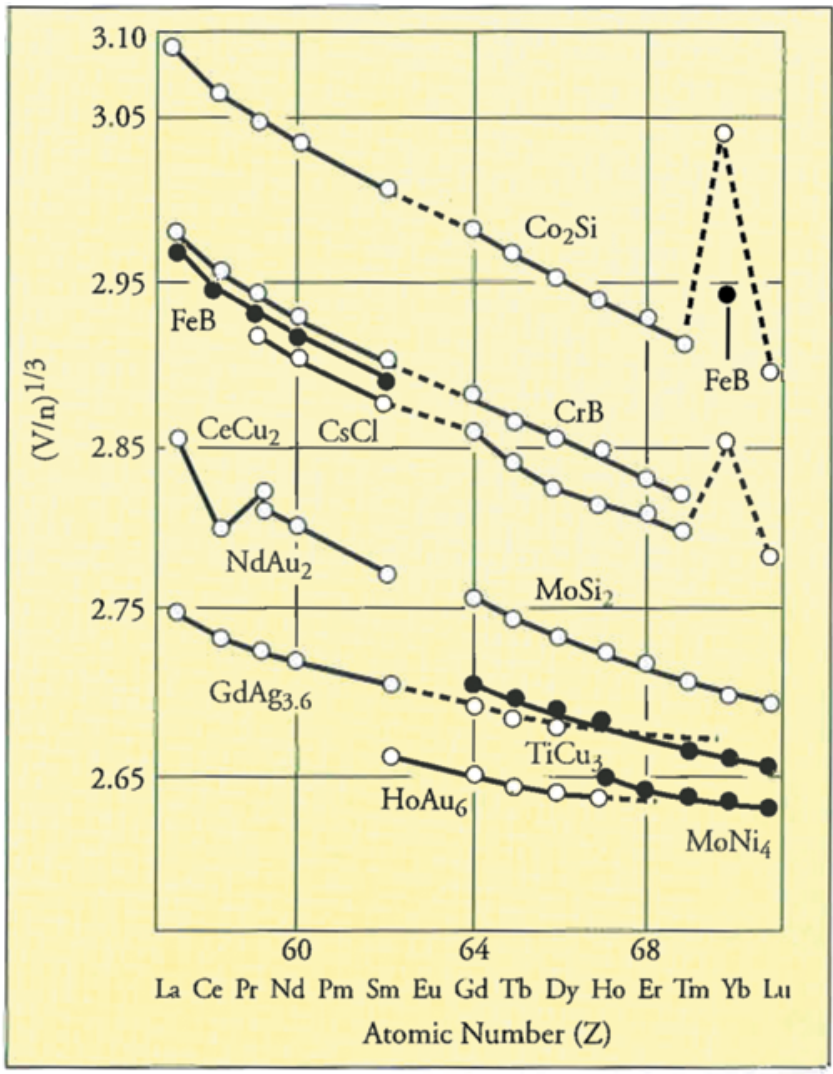

Figure 8 The mean atom volume $(V / n)^{1 / 3}$ of intermediate phases $A u_{x} R E$ versus the atomic number $Z$ of $R E$ metals for the different structural types 
Table 5 The Parameters $\alpha, \beta$ and $\omega$ for the Rare Earths in Gold

$\begin{array}{cccccccc}\text { Rare Earths } & \alpha & \beta & \omega & \text { Rare Earths } & \alpha & \beta & \omega \\ \mathrm{Sc} & 8.8 & 15 & 0.49 & \mathrm{~Tb} & 1.5 & 9.7 & 0.155 \\ \mathrm{Y} & 2.0 & 6.3 & 0.32 & \mathrm{Dy} & 2.3 & 9.5 & 0.242 \\ \mathrm{La} & 0.1 & 9 & 0.01 & \mathrm{Ho} & 3.92 & 9.3 & 0.42 \\ \mathrm{Ce} & 0.1 & 9.5 & 0.01 & \mathrm{Er} & 5.7 & 13.2 & 0.43 \\ \mathrm{Pr} & 0.1 & 12 & 0.008 & \mathrm{Tm} & 6.5 & 13.9 & 0.47 \\ \mathrm{Nd} & 0.2 & 9.5 & 0.02 & \mathrm{Yb} & 6.9 & 11 & 0.63 \\ \mathrm{Sm} & 0.3 & 11.5 & 0.026 & \text { Lu } & 7.7 & 15.2 & 0.51 \\ \mathrm{Gd} & 0.7 & 9.5 & 0.074 & & & & \end{array}$

$\alpha, \beta$ data taken from experimental phase diagrams

Obviously, the lower the $\omega$ value, ie the lower the $\alpha$ value and/or the higher the $\beta$ value, the greater will be the solute concentration at the solidification front in the liquid alloy. Therefore, a small $\omega$ value indicates that there is a tendency for the solute to be distributed or segregated along the grain boundaries after solidification thereby causing a tendency to embrittlement of the alloy. It is generally recognised that when $\omega<0.1$ and $\alpha$ is small the alloying elements may be harmful and may cause embrittlement. Similarly, the solute elements have a strengthening effect when $\omega$ is $>0.7$ and $\alpha$ is $>20$. The elements which are far from gold in the Periodic Table, which have a very small and even negligible solid solubility, have very small $\omega$ values and tend to segregate along grain boundaries. The elements close to gold in the Periodic Table, which have a high solid solubility and high $\omega$ values, will have a strengthening effect.

The characteristic parameters, $\alpha, \beta$ and $\omega$ have been calculated and are listed in Table 5 . The $\omega$ values are smaller for the light rare earths and larger for the heavy rare earths. They indicate that the solute rare earths tend to segregate along grain boundaries in gold alloys and may even form a continuous network along the boundaries in alloys containing a high concentration of rare earths. However, the segregation tendency of the light rare earths along grain boundaries is greater than that for the heavy rare earths. This tendency has been observed not only in Au-RE alloys but also in Ag-RE, Pd-RE and Pt-RE alloy systems (18 - 20).

The strengthening or embrittling effects of alloying elements characterized by the parameter $\omega$ show only a general trend. In fact, they depend on the solute concentration and the relevant structural changes. For microalloyed gold or gold alloys, elements that may be harmful in larger concentrations can often become strengthening elements when added as a trace to give a dilute concentration. In a dilute concentration range, the rare earths are effective strengthening agents for gold. The strengthening effects include both solid solution and precipitation strengthening.

The solid solution strengthening effect of trace elements in gold is related to two factors $(1,17)$. The first (A) is the ratio of the atomic weight of gold to that of the alloying element. It is approximately directly proportional to the ratio of the numbers of gold and solute atoms at a particular weight percentage. The second factor $(B)$ is the relative difference in atom size between the alloying element and gold where $B=\left(r_{M}-r_{A u}\right) / r_{A u}$. It is proportional to the amount of lattice distortion caused by the presence of the solute atom. The solid solution strengthening effect of the alloying element can be expressed roughly by the parameter $\mathrm{H}_{\mathrm{S}}=\mathrm{AB}$. Table 6 lists the strengthening parameter $\mathrm{H}_{S}$ for rare earth solutes in gold. The order of $\mathrm{H}_{S}$ values for the rare earth metals in gold is $\mathrm{H}_{S}(\mathrm{Sc}, \mathrm{Y}, \mathrm{Eu})>\mathrm{H}_{S}$ (light $\mathrm{RE}$ from $\mathrm{La}$ to $\left.\mathrm{Sm}\right)>$ $\mathrm{H}_{S}$ (heavy $\mathrm{RE}$ from $\mathrm{Gd}$ to $\mathrm{Lu}$ ). Therefore, as far as the solid solution strengthening of gold is concerned, the strengthening effect of Sc, Y, and Eu should be larger than that of the other rare earths, and the strengthening effect of the light rare earths should be larger than that of the heavy rare earths. This is attributed mainly to the relatively light atomic weights of $\mathrm{Sc}$ and $\mathrm{Y}$ and a larger atomic size difference for Eu and the light rare earths.

When compared with other elements in the periodic table, the solid solution strengthening effect of rare earths in gold is much greater than that for the transition metals and other metals. This is attributed mainly to the large atomic size difference between RE, especially the light RE, and gold. However, it is less than that for light metals such as $\mathrm{Be}, \mathrm{Ca}, \mathrm{Li}, \mathrm{Mg}, \mathrm{Sr}$, etc. where there is a large ratio of the numbers of atoms of the light metals to atoms of gold. 
Table 6 The Solid Solution Strengthening Parameters $\left(H_{S}\right)$ of Rare Earths and Other Elements in Microalloyed Golds

$\begin{array}{cccccccc}\text { Elements } & \mathbf{A} & \mathbf{B} & \mathbf{H}_{\mathbf{s}} & \text { Elements } & \mathbf{A} & \mathbf{B} & \mathbf{H}_{\mathbf{s}} \\ \mathrm{Sc} & 4.38 & 0.139 & 0.61 & \mathrm{Ge} & 2.71 & 0.051 & 0.137 \\ \mathrm{Y} & 2.22 & 0.25 & 0.56 & \mathrm{~Pb} & 0.95 & 0.213 & 0.202 \\ \mathrm{Eu} & 1.30 & 0.418 & 0.54 & \mathrm{Si} & 7.01 & 0.085 & 0.595 \\ \mathrm{RE}(\mathrm{L}) & 1.41-1.31 & 0.305-0.253 & 0.43-0.33 & \mathrm{Li} & 28.38 & 0.06 & 1.58 \\ \mathrm{RE}(\mathrm{H}) & 1.25-1.13 & 0.251-0.205 & 0.31-0.23 & \mathrm{Na} & 8.57 & 0.288 & 2.48 \\ \mathrm{Ag} & 1.83 & 0.002 & 0.004 & \mathrm{~K} & 5.04 & 0.576 & 2.90 \\ \mathrm{Cu} & 3.10 & 0.0114 & 0352 & \mathrm{Be} & 21.8 & 0.218 & 4.76 \\ \mathrm{Ti} & 4.11 & 0.014 & 0.056 & \mathrm{Mg} & 8.1 & 0.111 & 0.899 \\ \mathrm{Zr} & 2.16 & 0.103 & 0.22 & \mathrm{Ca} & 4.91 & 0.369 & 1.81 \\ \mathrm{Al} & 7.30 & 0.007 & 0.051 & \mathrm{Sr} & 2.25 & 0.492 & 1.11\end{array}$

$L=$ light rare earth metals; $H=$ heavy rare earth metals.

The limits of solid solubility of rare earths in gold fall as the temperature decreases. It is possible, therefore, that these systems are amenable to precipitation strengthening by solution treating the alloys, quenching and age hardening at low temperature. The precipitate phases in the gold-rich Au-RE systems are the gold-rich compounds such as $\mathrm{Au}_{6} \mathrm{RE}$ (for $\mathrm{La}, \mathrm{Ce}, \mathrm{Pr}, \mathrm{Nd}, \mathrm{Pm}, \mathrm{Sm}$, $\mathrm{Gd}, \mathrm{Tb}, \mathrm{Dy}, \mathrm{Ho}$ ), $\mathrm{Au}_{5} \mathrm{RE}$ (for $\mathrm{Eu}$ ) and $\mathrm{Au}_{4} \mathrm{RE}$ (for $\mathrm{Er}$, $\mathrm{Tm}, \mathrm{Yb}, \mathrm{Lu}, \mathrm{Sc}$ ). Gafner (21) has calculated the amount of hardening phase for gold alloys containing $1 \mathrm{wt} \%$ alloying addition. Table 7 gives the probable strengthening effect for various solute elements. The parameter $\mathrm{H}_{\mathrm{p}}$ in the last column is the product of the fraction of the $1 \%$ alloying addition precipitating in atomic percentage multiplied by the number of atoms of the solute in the precipitating intermetallic compound. This is taken as an indication of strengthening effectiveness. The precipitation strengthening effect of the rare earths is quite notable, although it is inferior to that of titanium ( $\mathrm{Ti}$ ) and zirconium $(\mathrm{Zr})$. However, when considering a lower $\mathrm{RE}$ concentration, e.g. only an 0.5 $w t \%$ addition, the solubility data at $400^{\circ} \mathrm{C}$ indicate that a precipitation strengthening effect would not be expected. Some experimental results have proved that gold alloys containing $0.5 \%$ heavy RE or less do not display age hardening with the exception of the Au- $0.5 \% \mathrm{Y}$ alloy (17, 22). The strengthening of gold by the addition of yttrium can be attributed to appreciable solid solution strengthening (see Table 6) plus the precipitation strengthening. In addition, oxides of the rare earths may form due to internal oxidation during alloy preparation and processing and this is probably a factor causing strengthening in gold alloys in certain conditions.

Since rare earths have a tendency to segregate along the grain boundaries, they are often used in gold alloys only in trace or dilute concentrations. There is no lack

Table 7 The Parameter $H_{p}$ for the Precipitating Phase in Gold Alloys Containing 1 wt\% Solute after Solution Treating, Quenching and Ageing at $400^{\circ} \mathrm{C}(17,21)$

\begin{tabular}{|c|c|c|c|c|c|c|c|}
\hline \multirow{2}{*}{ Solutes } & Solubility & Solubility & \multirow{2}{*}{$\mathbf{H}_{\mathrm{p}}$} & \multirow{2}{*}{ Solute } & \multirow{2}{*}{$\frac{\text { Solubility }}{\text { at } 800^{\circ} \mathrm{C}}$} & \multirow{2}{*}{$\frac{\text { Solubility }}{\text { at } 400^{\circ} \mathrm{C}}$} & \multirow{2}{*}{$H_{p}$} \\
\hline & at $800^{\circ} \mathrm{C}$ & at $400^{\circ} \mathrm{C}$ & & & & & \\
\hline $\mathrm{Ti}$ & 1.2 & 0.4 & 12.5 & Co & 2.2 & 0 & 3.3 \\
\hline $\mathrm{Zr}$ & 2.0 & 0.3 & 7.5 & $U$ & 0.7 & 0.1 & 2.0 \\
\hline Tb & 1.2 & 0.3 & 5.6 & Ru & 1.0 & 0 & 2.0 \\
\hline Dy & 1.9 & 0.3 & 5.6 & $\mathrm{Rh}$ & 0.6 & 0.2 & 0.8 \\
\hline Ho & 3.2 & 0.4 & 4.9 & TI & 1.0 & 0.5 & 0.5 \\
\hline $\mathrm{Er}$ & 4.8 & 0.4 & 3.5 & & & & \\
\hline
\end{tabular}


of examples of applications with microalloyed high carat golds and with bonding gold wire alloys (23 28). Gold alloys containing trace or dilute concentrations of RE metals have been used extensively in China as electric contact and potentiometer winding materials $(29-31)$.

\section{CONCLUSIONS}

The alloying behaviour of the RE metals with gold is characterized by the formation of a series of eutectic reactions and limited terminal solid solubility. The maximum solid solubilities of RE metals in gold increase as the lanthanide contraction becomes larger (ie the atomic radius becomes smaller). Thus, heavy $\mathrm{RE}$ metals have higher solid solubilities than light RE metals. The alloying behaviour of scandium (Sc) and yttrium (Y) with gold is similar to that of lutetium $(\mathrm{Lu})$ and dysprosium (Dy), respectively.

The Hume-Rothery and Darken-Gurry criteria for solid solubility of most alloys are not directly relevant to the solubility of RE metals in gold; but they can be relevant when the solid solubilities are greater than 1.0 at\% RE metal, the atomic size difference is less than $25 \%$, and the difference in electronegativity is less than 0.7 units. A series intermediate phases formed in $\mathrm{Au}$ RE systems are fusion-type compounds with 14:51 (for light RE), 1:3 (for heavy RE) atomic ratios, respectively. 1:2 and 1:1 RE:Au atomic ratios are formed by ' melting, and decomposition-type compounds, formed via peritectic reactions, have atomic ratios of 1:6, 1:5, 1:4, 2:1, etc, RE:Au.

The reduced temperature maps based on the dependence of $T_{e u}\left(T_{m}, T_{p}\right) / T_{r}$ on atomic number of the RE metals show a similar regularity: the reduced temperatures decrease with the increase in atomic number of the RE metals, with the exception of cerium (Ce) and ytterbium ( $\mathrm{Yb}$ ) which have anomalously high values of reduced temperatures.

The type of physical metallurgy survey described in this review paper should assist alloy developers to predict some unknown phase relationships or reactions for Au-Re systems and to select alloying elements for practical or commercial applications.

\section{ABOUT THE AUTHOR}

Professor Ning Yuantao is a Research Fellow at the Kunming Precious Metals Institute in China, working on a variety of research projects related to precious metals and rare earth materials. He has considerable scientific achievements and has won national prizes. His work has also been concerned with research into applications for gold and its alloys.

\section{REFERENCES}

1 X. Zhou and Q. Li, Precious Metals, 1994, 15(2), 1

2 H. Okamoto and T.B. Massalski, 'Phase Diagrams of Binary Gold Alloys', Metals Park, Ohio, 44073, 1987

3 K.A. Gschneidner Jr. and E.W. Calderwood, Bull. Alloy Phase Diagrams, 1983, 4(4), 364

4 P.E. Rider, K.A. Gschneidner Jr and O.D. McMasters, Trans. Met. Soc, AIME, 1965, 223,1488

5 J.T. Waber, K.A. Gschneidner Jt, A. Larson et al Trans. Met. Soc., AIME, 1963, 227, 717

6 W. Gordy and W.J. Thomas, J. Chem. Phys., 1956, 24, 2

7 A.R. Miedema, J. Less Common Met., 1973, 32, 117

8 K.A. Gschneidner Ji: and F.W. Calderwood, in 'Handbook on the Physics and Chemistry of Rare Earths', Vol.8, ed. K.A. Gschneidner Jr.. and L. Eyring, NorthHolland Physics Publishing, Amsterdam, 1986

9 Y. Ning, Precious Metals, 2000, 21(1), 42

10 O.D. McMasters, K.A. Gschneidner Jr., G. Bruzzone and A. Palenzona, J. Less Common Met., 1971, 25, 135.

11 W. Hume-Rothery and G.V. Raynor, 'The Structure of Metals and Alloys', 3rd Edition, London, Inscitute of Metals, 1954

12 K.A. Gschneidner Jt. and O.D. McMasters, Metall. Trans., 1970, 1, 1961

13 Y. Ning, Precious Metals, 2000, 21(2), 46

14 Y-N. Ning and Y-T. Ning, J. Mater. Sci. Technol, 1997, 13(1), 21

15 K.A. Gschneidner Jr., in 'Science and Technology of Rare Earth Materials, ed. E.C. Subbarao and W.E. Wallace, New York, Academic Press, 1980, 51

16 B.B. Golyev, in 'Synthesis of Alloys', Metallurgy Press, Moscow, 1984

17 C.W. Corti, Gold Bull., 1999, 32(2), 39

18 Y. Zu, G.Qi and D. Deng, Precious Metals, 1992, 13(1), 24

19 F. Wen, Y. Ning, H.Zhao and D. Deng, Precious Metals, 1992, 13(3), 10

20 F. Chen, C. Hu and H. He, Precious Metals, 1988, 9(3), 15

21 G. Gafner, Gold Bulh, 1989, 22, 112

22 M. Poniatowski and M. Clasing, Gold Bull, 1972, 5, 34

23 Ogasa Kazuo and Sugano Mikihiro, Japanese Patent Application JP 08157983 A2

24 Takahashi Hironori and Kojima Kyokazu, Japanese Patent Application JP 08031253 A2

25 Mulkoyama Koichiro, Kurihara Kenichi, Yasuhara Kazuhiko and Takaura Shin, Japanese Patent Application JP 080130602 A2

26 K. Ogasa, Three O Company, Japan, WO Patent 96/31632, 1995

27 Mitubishi Material Corporation, Japan, Japanese Patent 07265112 A2, 1993

28 Tanaka KK, Japan, Japanese Patent 7090425, 1993

29 Y. Ning, Precious Metals, 1994, 15(2), 61

30 B.Feng, Z. Tong, J. Du and Y. Xic, Precious Metals, 1995, 16(1),16

31 Y. Ning, in 'Potentiometer Technology', Symposium on Potentiometer Materials and Technology (in Chinese), 1973, 92

32 A. Fandelli and A. Palenzona in 'Handbook on Physics and Chemistry of Rare Earths', Vol. 2, ed. KA. Gschneidner, Jr and L. Eyring, North Holland Publishing Co, Amsterdam, 1979

33 A.R Miedema, Philips Technical Review, 1976, 36 (8), 217 